\title{
Deprivation, Dehumanisation and Defective Urban Planning: A diagnostic study of the Slum Problem in India
}

\author{
Prakhar Bisht. \\ Research Scholar, Kumaun University, Nainital - 263002
}

\begin{abstract}
This article is a diagnostic study to find out why slums exist in the metropolitans and how can the slum problems be improved. This study was done with the help of participant observation and interview. Slum problem in India is mostly found in the metropolitan cities. The metropolitans attract the slums. The slum dwellers live in sub-human conditions and they are the victims of the exploitation of the wealthy upper class. They are poor, malnourished and these people live in an unhygienic atmosphere. They are over-populated, congested and a sharp contrast to the urban malls and IT parks which are well-planned and prosperous. This study tries to find out the loopholes in urban planning. It also tries to compare a slum area with a mall. We also investigate about the attitudes of the slum dwellers. How the slum population is neglected by the politicians and the bureaucrats who are on a lookout of power fulfillment and financial gains. In this paper census data had been used to compare the metropolitan cities and people living in the slums have been interviewed. The slum areas suffer from lack of education, diseases, parental negligence, superstition, anti-social activities, alcoholism, drug abuse and lack of proper infrastructure. Many children have dropped out from their schools and do odd jobs to sustain their families. Girls are married at an early age. There has been a migratory pattern for the slum dwellers who have settled here from their villages. They mistrust the police and the government representatives. In the concluding part some measures have been suggested to uplift the slums and solutions to overcome the slum problem in India.
\end{abstract}

Key words: Sub-human conditions; loopholes; attitudes; sex-ratio; malls

\section{Introduction:}

Whenever we go by train from one city to another, the sight of the slums in the midst of the metropolitan provokes us to find out why do we have to face such a situation? We, who are city dwellers, like to stay in comfort and the whole purpose of doing a job and going to the office is that at the end of the day we can rest in our homes. This is in contrast with the situation of the slums which do not even have facilities of water pipes and sewage, no electricity, houses constructed out of straws and deprived of bricks, roofs not fixed, the pavements are slushy and the smell of sewage is everywhere. Garbage is thrown everywhere and when the monsoons are on the whole slum area becomes muddy and water gets filled till the knee-caps (Mumbai). The condition in the metropolitans is very adverse. Every metropolitan city has a slum area in it. Slum areas are the centers of deviancy and anti-social elements. It is usually the village folk who migrate from their villages and settle in the slums.

If we compare the slum population city-wise we will find many similarities between them. Every city has a slum and all the slums have slum problems.

The following is the table showing latest data related to slums found in the metropolitan areas with a population of more than one million.

TABLE I

\begin{tabular}{|l|l|l|}
\hline City & \% of slum population & Sex -Ratio \\
\hline Mumbai & 54.06 & 770 \\
\hline Delhi & 18.74 & 780 \\
\hline Kolkata & 32.48 & 805 \\
\hline Bangalore & 10.02 & 947 \\
\hline Chennai & 18.88 & 974 \\
\hline Ahamedabad & 13.46 & 850 \\
\hline Hyderabad & 17.23 & 938 \\
\hline Kanpur & 14.42 & 857 \\
\hline Pune & 19.39 & 928 \\
\hline Surat & 20.89 & 701 \\
\hline
\end{tabular}


From this data two things can be generalized. First is that the greater is the size of the metropolitan, the greater is the slum population. Secondly, the greater is the slum population the lesser is the sex-ratio of that slum area. With this little information we can deduce that the slums have their own problems like over-crowding and overpopulation. But what cannot be deduced are the menial and the degrading conditions in which the people are living. For that, a field visit to the slum area is a prerequisite.

The tragedy in India is that where it has huge I T parks and posh residential area, it also has the slums which are growing in number every day. As more and more cyber cities are being created so are the number of slums which are surrounding it. Thus, two contrasting cultures are being created at the same time and they are both living their lives in their own different worlds. One is wealthy and considered the pride of the nation while the other is poor and is neglected by the elites and the rich strata of the society. These are the contrasting states of prosperity and deprivation. These are the two diverging perceptions of India.

\section{Objectives:}

- To find out the characteristics of the dehumanizing condition.

- To diagnose why the slums suffer from deprivation.

- To examine loop-holes in urban planning.

- To compare a slum area with a Special Economic Zone.

- How accurate are the attitudes of the urbanites towards the slum dwellers.

\section{Profile and Design of the Respondents:}

This study was conducted in the slum area of Kidwai Nagar in Haldwani in the Nainital district in the state of Uttrakhand. Haldwani is a big commercial centre of the Kumaun region and is expanding just like Delhi. As the time is passing more and more of the surrounding villages are getting included in it. The population of the state of Uttrakhand is around 8.4 million. The land area is about $55,843 \mathrm{sq} \mathrm{km}$. The region is mostly hilly and $12 \%$ of the population falls in the plains. It has tremendous potential for developing tourism industry. Apart from Kidwai Nagar many slums can be seen near Haldwani Railway Station till a long stretch.

\section{Methodology:}

Questions in the form of interview-schedules were distributed among 30 residents of the slum. Questions were asked and as they spoke their answers were recorded. Those respondents were preferred who were a little bit literate at least till primary schools so that they could understand the questions properly and would be not very narrow-minded. Secondly, they would not feel awkward in an interview situation.

In addition the field of study was also observed. Photographs were taken and studied to find out the distinguishing characteristics of the slum. The main focus were the slum houses, roads an pavements, roofs, water-pumps and public water taps, sewage pipes and drains etc. This gave us some clues about the environment through naturalistic observation.

\section{Sub-Human Conditions: Defecation out in the Open}

This is one of the most dehumanizing effects of the slums. There is no planning when slums are created therefore there is also no planning of the sanitation facilities in the slums. Toilets are almost unavailable in the slum area and even if there is one it is poorly maintained. Most of the slum dwellers are unaware of gravity of this situation. They are oblivious of the fact that they are polluting the environment. It is very degrading in the case of women. It is ironic that in a country like India which boasts that almost every one has a mobile phone cannot even build a decent toilet-facilities for every woman.

Nearly $65 \%$ of Mumbai's population of 13 million, i.e., about 8 million people live in slums, of which $50 \%$ live in authorized slums with some toilet facility. The other 50\%, i.e., about 4 million slum residents have no choice but to ease themselves in open spaces, along roads, highways, railway tracks, parks, playgrounds, open plots and beaches. During monsoons, this excreta flows through open drains and nallas into the storm water drains and gets discharged right near the coast (bpct.org).

Most of the slum dwellers have migrated from the rural areas and they have a habit of defecating out in the open. Since children are not sent to public toilets, they develop a bad habit in the early age to defecate in the open. The bathroom use of the women is often avoided in the public toilets as they are badly maintained and very claustrophobic.

The slum dwellers live in an animal-like condition. For most of them lavatories are not available and they ease themselves out in the public. When asked about how the residents ease themselves out in the public about $20 \%$ replied than they defecate in open land. Thus, we can clearly see how these unhygienic conditions are a source of numerous spreading diseases. About 40 percent replied that they attend to the call of nature in public lavatories. It was found out that the condition of these lavatories is very bad and secondly that there is line of about 10-12 people during the early mornings in front of it. Also, when asked how often they took a bath 
about $60 \%$ replied that they took bath on a monthly basis. According to World Health Organisation Unicef report of 2012 about $66 \%$ of India's population is deprived of toilet facilities. The following table shows India's comparison with the other countries:

TABLE II

\begin{tabular}{|c|c|}
\hline COUNTRY & DEPRIVED TOILET FACILITIES \\
\hline INDIA & $66 \%$ \\
\hline NEPAL & $69 \%$ \\
\hline AFGHANISTAN & $63 \%$ \\
\hline BHUTAN & $56 \%$ \\
\hline PAKISTAN & $52 \%$ \\
\hline BANGLADESH & $44 \%$ \\
\hline
\end{tabular}

\section{Organismic Defect: The Shelter -Less Population}

Herbert Spensor, one of the greatest proponents of structural-functionalism once gave an image of society as an organism having various organs. He also said that if some organ gets infected it affects other organs of the organism too. For example if the kidney gets infected the liver also stars working improperly. In the same way the condition of slums affects every one. Asis Nandy ${ }^{1}$ has once aptly remarked that slums represent the dark side of the cities. This is because most of the people living in it are shelter-less and their homes are not legitimately recognized. They also indulge in many anti-social activities like drinking, drugs, gambling and prostitution. The women in the slums are unsafe when the men go out to work. Calcutta has the highest percentage of urban homeless population followed by Mumbai and then Delhi.

When asked what the respondents do when someone falls ill in their house or neighbourhood, about $30 \%$ replied that they visit a shaman or a witch doctor. Only $15 \%$ replied that they'd visit a private doctor. This may be because they most of the slum-dwellers are very superstitious and secondly they don't have the expenses to pay for medical facility.

When asked who they think practices authority over them and on whom they are bound to obey about $55 \%$ replied that a local 'dada' or an anti-social element exercises his authority over them. About $20 \%$ said that the police harass them This shows the condition of deviance in the slum area and because of the presence of anti-social elements the police are in look out of culprits and constantly interrogates the innocent victims.

When asked how often they drink. About $24 \%$ replied that they drink every-day. This shows that a considerable part of the population, are heavy drinkers. They ill effects of heavy drinking are as we already know is the deterioration of health, wife-battering, negligence of children and absence from work (if there is any).

The slums are also the retreat of the drug-dealers. When asked which drugs are sold in the slums the most, a considerable 37\% replied that 'charas' and 'ganja' are the most often consumed drugs. Drug-addition has long term problems and it take many years to rehabilitate a person.

Also alarming is the custom of early marriages in the slum area. About $19 \%$ replied that girls are married at the age of 15 . This is the cause of not only high maternal mortality but also the cause of the decreasing sex-ratio. Later in life it would also result in infant mortality especially, if the child is malnourished or underweight.

When asked how much interval in kept between two successive births, $60 \%$, which is a very high number, replied that there is no gaps between successive births. This shows the reason why sex ratio is so less probably due to high maternal mortality and high infant mortality.

\section{The Negligence of the State: Urban Planning and the Slums}

If a society wants to progress, wants to develop and follow the example of the developed western countries, it has to depend on the government or the state. But, the slums are neglected. It has been found that most of the slums are neglected by the government during the development process. Most of the land is bought illegally and it is used to build residential areas for the wealthy upper class. The bureaucrats exploit the poor to get some quick money out of this deal from the affluent who have plenty of black money. The corruption among the bureaucrats have led to red - tapism and increased delay of the development of the slum area.

When interrogated, how often does the running water come during the day $90 \%$ replied that it only comes for about two hours and that too during the late nights where the water has to be stored for the consumption of the next day. This shows the unhygienic conditions prevailing due to unavailability of water. Stored water also becomes contaminated with the passage of time and leads to diseases like dengue, typhoid and cholera. The health department and the department of women and child development have neglected their duties in this area. 
When asked what type of changes the slum dwellers would want from the government $35 \%$ were in favour of better sanitation and $22 \%$ wanted electricity especially during the night hours of the day. Some of the children aged between 6-15 years go to school and they are deprived of the electricity and so they can't concentrate in their school work. Besides, many of the parents don't encourage their children to go to school. Sanitation on the other hand poses a bigger problem as it is the source of all the long-term diseases coupled with dehumanizing conditions.

The distrust for the government representatives can be deduced from the following interaction. When asked whether the politicians fulfill their promises once they visit there are $85 \%$ who replied never. This shows the situation of hopelessness and growing mistrust towards the government among the slum-dwellers. The politicians are seen as the people whose motives are to come there to earn votes and cling to their seats of power.

A well built house provides a sense of security to a person living in it. Abraham Maslow 2 is of the opinion that once the security needs are fulfilled only then the needs of belonging and self actualization are achieved. When asked what material is used to build their houses $75 \%$ replied that their houses are build out of mud and roofs out of dilapidated tin sheets which are pressed down by stones and bricks so that during strong winds they do not fly away. Also during the monsoons or "cloud-burst" the water percolates inside the houses through the mud walls.

During observation it was found that there were very few sources of water like hand pumps and publicwater taps. The water pumps (also called tullu pumps ${ }^{3}$ ) were in a very bad condition and were unable to draw water. When asked how many hand-pumps there are in good working condition the answer was three. This is very small a number for a population of about more than 1,000 residents. The reason for the lack of water might be that most of the water gets diverted through the pipes to the posh resident area nearby, where most of the wealthy upper-class lives.

\section{Repulsive Concerns: Attitudes Towards Slum Dwellers}

Generally the attitudes of the onlookers are that the slum dwellers are uneducated, disease prone, badly supervised children, superstitious, deviant, alcoholics and drug-addicts (Warwadi Area, Pune). The movie 'slumdog-millionnaire ${ }^{4}$ has vividly shown how a poverty prone boy, born in the slums fights the challenges of his degrading life and ultimately achieves success. His brother on the other hand becomes an anti-social element when he is just a teenager. We also witness when these children get uprooted from their families how the mafia and another gang of anti-social elements exploit them deliberately try to destroy their vision so that they could look like a beggar and ask for alms by singing bhajans ${ }^{5}$.

When asked how much educated the slum dwellers are $30 \%$ replied that they were only educated up to primary level. They could be categorized as literates because they sign their names but they cannot really read and write. The rest are 'angootha chap ${ }^{6}$.Due to this they are exploited by the shop-keepers when they ask for rations through their BPL cards.

One another reason why the family is so poor is the fact that they have too many children. When asked how many children as parent has it was found out that about $50 \%$ of the family has more than four children. Many men generally don't have adequate knowledge about contraceptives and pills to avoid pregnancy. Secondly, the desire for the male child is another cause for big families.

The problem of girl child and declining sex ratio is another issue. When asked how often the girl infants get tetanus injections about $48 \%$ replied in the negative. This shows that there is discrimination between males and females. Birth of the female is not rejoiced and which further forces the husband and wife to have one more child.

When asked what kind of work the women do? It was found that that $40 \%$ were labourers, $30 \%$ worked as house-maids in the nearby residential area and $10 \%$ were garbage collectors. This shows that the family cannot sustain themselves from just one member working in the family. They require many hands to earn the bread.

Most of the children are drop-outs from schools. $30 \%$ wash dishes in a dhaba ${ }^{7} .20 \%$ spend their time car-washing and cleaning. 10\% do nothing. These children might be involved in anti-social activities.

A slum resembles a really dilapidated village. This is because most of the slum-dwellers have migrated in the village in the search of jobs. In other words the push factors and the pull factors jointly contributed to their migration in the cities. The push factors are lack of income, no employment, no land for agriculture and indebtedness whereas the pull factors are glamour of the city, industrial jobs, more pay and greater opportunity to indulge in gambling, alcoholism and drug-addiction. When asked how the slum-dwellers settled in this area about $30 \%$ replied that they migrated from the village. 


\section{SEZ, EPZ and the Malls: The Growing Inequality}

Whereas the slums are living in deprivation, the government is planning to find out spaces in the country where it can place special economic zones, export processing zones and huge malls where many multinational companies will contribute their share There is a growing need for the government to increase the countries national income from the FDI. In these zones many malls will be set up, many call centers will be erected, and export processing areas are being built. The objectives of SEZ Act are:

(a) Generation of additional economic activity.

(b) Promotion and export of goods and services.

(c) Promotion of investment from domestic and foreign services.

(d) Creation of employment activities.

(e) Development of infrastructural facilities.

When the government can think of passing the bill for the economic development why cannot it pass the bill for the social and economic development of the slum areas?

As these areas will develop, the contrast between the rich and the poor will become even more prominent. This can be stated as the underdevelopment of the development. Most of the metropolitan areas will start to resemble the slums of Greater Mumbai where there is a kilometers of stretch of the slum area. The slum population will keep on growing as more and more people will be pushed from the village sectors and move to the cities. These people already have poor purchasing power and it will grow even worse. The rich will keep getting richer and the poor will keep getting poorer. According to the views of Karl Marks this polarization will ultimately lead to pauperization and later conflict may erupt.

\section{MALLS:}

They are the present Indian retail scenario that is attracting both domestic and international investors. The purchasing power of the customer is on a constant rise. The once quiet cities of Gurgaon, Noida and Pune are the leading centers for the malls because of their close proximity to the metros. These were once small farm yards are now main centers of mall culture. Many multi-national brands are promoted here. The owners of the malls are busy planning the erection of glass and steel which are futuristically designed. Malls are based on a consumerist philosophy and the people are rich and have a high purchasing power and spent almost all of their monthly incomes in the malls. A very less percentage of their money is actually saved in the banks and they spend money freely. These people buy the most expensive brand clothes, eat in the most expensive restaurants and every six months buy a new smart phone for themselves.

\section{Conclusion:}

This is a never ending study whose main aim was to diagnose the problems of the slum. Thus, the most we can do is to give appropriate measure to improve the conditions of slums so that they can live like proper human beings. Coming back to the objectives of the study we can now suggest the following measures for improvement:

Firstly, people should be educated not to defecate in open area and children should not be encouraged. There should be more awareness programmes about this view. Secondly, public toilets which are very small and claustrophobic should be made more comfortable. Thirdly, each house should have a toilet and should be well connected to the under ground sewage pipes. The government should not cut water and provision of water tanks should be available so that the slum-dwellers can at least live in a hygienic condition.

Secondly, to get rid of crime in the area a team of social worker should go there and educate the youth not to indulge in anti-social activities. The police should be instructed to stop harassing the innocent residents. Gangs which exercise authority should be immediately arrested for there wrong doing and should be sent to reform jails. Drug addiction should be stopped and drug dealers should be put behind the bars. There should be a programme to rehabilitate the heavy drinkers and shops which sell local made cheap liquor should be shut down. The social workers should also educate the families of the slum areas to avoid marrying their daughters at an early age as it is illegal and results in maternal mortality and infant-mortality.

Thirdly, most important is the role of the government. The basic civic amenities should at least be adequate. Water should not come at odd hours of the night. Electricity should be there during the night hours. The sewer holes should be covered. Water connections should be available in each house. There should be better housing. The roof should be fixed and not held temporarily by stones. The politicians should fulfill their promises. This will show that the government mechanism is working properly. The houses should be solid and built with bricks and cement which is durable and not cheap. The capitalists, entrepreneurs, developers, contractors, industrialists and land lords must be checked so that they do not do whatever they want with public land. At the same time the slums should be persuaded not to encroach upon other land. The government should build adequate housing for them. The behavior of the staff of the government hospital should not be rude and 
social workers should discourage them to consult cheat doctors and amateur medical professional who sell their medicines through tents.

Fourthly, the attitudes towards slum dwellers should be changed. Schools should be set up in the slum are where even the drop-outs are educated at a cheap price. The slum dwellers should be educated about the use of contraceptives and sexually transmitted diseases like HIV Aids. The contraceptives should be available to them at a cheap price. They should be educated about family planning and consequences of a large family. When the girl is born giving tetanus injections to her should not be avoided. Otherwise it will lead to a weak offspring and could result in early death. It will also lead to a decrease in the child-sex ratio. The girls should be educated and girl schools, especially for girls should be set up. The drop-out girls should be encouraged to be again readmitted to the schools. A sympathetic attitude should be developed towards the women who are housemaid, sweeper, garbage collector, factory workers and labourers. Children who have deviated and have now become juvenile delinquents due to overcrowding, parental misdemeanour, lack of parental control and discipline at home, a broken home should be rehabilitated. People who have migrated from the village should be given employment as they have lost all their possessions and money to reach the city.

Lastly, the government should foster the development of not only the special economic zones but also the slums. Just because the slum area cannot give any return like the special economic zone, it should not be neglected. Here economic development is more important than social development. According to Kim social development means to attain those goals which majority of people living alone without society can demand their share of available social resources. Thus the slum dwellers need to become empowered so that they can demand from the government their human rights. He talks about structural flexibility. The minorities should initiate conflict to bargain for their share of resources. Asish Nandy, a prominent social theorist has explained the more the slums become overcrowded the more are the chances of a riot. Thus the government needs to increase the rate of social development, especially with respect to the slums so that the riots can be controlled and overcrowding can be checked.

\section{NOTES:}

1. Asis Nandy is a sociologist, cultural critic, and a futurist. He has been Director, Centre for the Study of Developing Societies, Delhi, and is now the ICSSR National Fellow there.

2. Abraham Maslow(1908-1970) was a humanistic psychologist. He was also a therapist. He contrasted the people with creative power with the people great mass of people who work only to satisfy their animal needs for food, shelter and safety.

3. In the local regional language hand pumps are called 'tullu pumps'.

4. Slumdog Millionnaire is an Oscar award winning movie based on slum life.

5. Bhajans are songs of devotion sung for Hindu Gods.

6. Angootha chap is a layman term for a person who cannot read or write even his own name and uses his thumb-print to prove his identity.

7. Dhaba is a public restaurant which is much cheaper than a normal restaurant and mostly truck drivers come there to have lunch and dinner.

\section{References:}

[1]. Ahuja Ram (2012).Social Problems in India.Jaipur: Rawat Publications.

[2]. Dube S.C(1990) Indian Society. New Delhi: National Book Trust.

[3]. Gottdiener Mark.(2000).New Forms of Consumption:Consumers, Culture, and Commodification; Rownan and Little Field.

[4]. Million Cities of South India.(2009) Retrived March 27 from: http://www.indianlinepages.com/population/slum-population-in-indiahtml

[5]. Mohanty Swati and Mohanty C.N.P(2005).Slum In India. APH Publishing.

[6]. Nandy Ashis.(2007). Time Treks: The Uncertain Future of Old and New Despotisms. Ranikhet: Permanent Black.

[7]. Palit Amitendu, Bhattacharjee Subhomay.(2008).Special Economic Zones In India:Myths and Realities. Anthem Press.

[8]. Rao Manohar.P.(1991).Environment and upliftment of slums in India. Vohra Publishers and Distributers

[9]. Rao Ratna. R.(1990) Social Organization In An Indian Slum. Mittal Publication.

[10]. Sekher T.V.(1997). Migration and Social Change. Rawat Publications.

[11]. Urban sanitation.(2010). Retrieved March 1,2012,from Finish: http://www.finishsociety.com/page.php?page_id=36 